\title{
Impact of COPD on prognosis of lung cancer: from a perspective on disease heterogeneity
}

This article was published in the following Dove Press journal:

International Journal of COPD

\author{
Wei Wang ${ }^{1, *}$ \\ Shuang Dou ${ }^{1, *}$ \\ Wenyan Dong ${ }^{2}$ \\ Mengshuang $\mathrm{Xie}^{\prime}$ \\ Liwei Cui ${ }^{1}$ \\ Chunyan Zheng' \\ Wei Xiao'
}

'Department of Pulmonary Medicine, Qilu Hospital, Shandong University, Jinan, People's Republic of China;

${ }^{2}$ Department of Geriatric Medicine, The Second Hospital of Shandong University, Jinan, People's Republic of China

*These authors contributed equally to this work
Correspondence: Wei Xiao;

Chunyan Zheng

Department of Pulmonary Medicine,

Qilu Hospital, Shandong University,

107 Wenhua West Road, Jinan 2500I2,

People's Republic of China

Tel +8653I 8216 6294

Email xiaowei4226@163.com;

chyzhengdoc@163.com
Background: COPD is an important comorbidity of lung cancer, but the impact of COPD on the outcomes of lung cancer remains uncertain. Because both COPD and lung cancer are heterogeneous diseases, we evaluated the link between COPD phenotypes and the prognosis of different histological subtypes of lung cancer.

Methods: In this retrospective study, subjects with a newly and pathologically confirmed diagnosis of lung cancer were enrolled from patients preparing for lung cancer surgery. All participants underwent pulmonary function test (PFT). The diagnosis of COPD was based on GOLD criteria. Lung cancer subtypes and COPD phenotypes were categorized by WHO classification of lung tumors and computer quantitative analysis of PFT. The HRs were estimated by Cox regression analysis.

Results: Among 2,222 lung cancer patients, 32.6\% coexisted with COPD. After adjustment for age, sex, body mass index (BMI), smoking status, and therapy method, COPD was significantly associated with the decreased overall survival (OS) of lung cancer (HR 1.28, 95\% CI 1.05-1.57). With the increased severity of COPD, the OS of lung cancer was gradually worsened (HR 1.23, 95\% CI 1.08-1.39). But surgical treatment and high BMI were independent prognostic protective factors (HR 0.46, 95\% CI 0.37-0.56; HR 0.96, 95\% CI 0.94-0.99). Moreover, in terms of disease heterogeneity, emphysema-predominant phenotype of COPD was an independent prognostic risk factor for squamous carcinoma (HR 2.53, 95\% CI 1.49-4.30). No significant relationship between COPD phenotype and lung cancer prognosis was observed among adenocarcinoma, small cell lung cancer, large cell lung cancer, and other subtype patients.

Conclusion: These findings suggest that COPD, especially emphysema-predominant phenotype, is an independent prognostic risk factor for squamous carcinoma only.

Keywords: lung cancer, COPD, prognosis, histology, disease heterogeneity

\section{Introduction}

Lung cancer and COPD are both devastating diseases. Lung cancer is the most frequently diagnosed cancer and the leading cause of cancer-related deaths worldwide, ${ }^{1}$ with approximately 10\%-20\% 5-year survival rate. ${ }^{2}$ It has become the fifth cause of deaths globally. ${ }^{3}$ In 2015, an estimated 610,200 patients died due to lung cancer in China. ${ }^{4}$ COPD is another common pulmonary disease that imposes a significant burden in terms of health care costs, disability, and impaired life quality. ${ }^{5}$ In 2010 , COPD accounted for about 5.2 million deaths ${ }^{6}$ and ranked third among the cause of deaths globally. ${ }^{3}$ Both lung cancer and COPD have been the most challenging medical issues faced by China, even entire world.

Lung cancer and COPD are closely related ${ }^{7}$ and share many common risk factors, especially cigarette smoking. ${ }^{8-11}$ Whereas previous studies have reported an increased 
risk of lung cancer due to COPD by 2- to 6-fold regardless of smoking habits, ${ }^{12-15}$ even in nonsmokers. ${ }^{16}$ Meanwhile, COPD is considered to be an important comorbidity of lung cancer, and about $40 \%-70 \%$ of lung cancer patients coexist with COPD. ${ }^{13,17,18}$ Therefore, several studies have attempted to investigate the relationship between COPD and prognosis of lung cancer. Researchers have pointed out COPD as an important risk factor for respiratory-related complications and postoperative recurrence of non-small cell lung cancer (NSCLC) ${ }^{19}$ and found that lung cancer coexisting with COPD led to poor prognosis. But a few other researchers reported contradictory results. ${ }^{20}$ The impact of COPD on the prognosis of lung cancer remains uncertain and needs to be further elucidated.

Lung cancer and COPD themselves are heterogeneous diseases with different pathological changes, clinical manifestations, and outcomes. So, we speculated that the heterogeneous nature of the two diseases played an important role in the relationship between COPD and lung cancer prognosis. Generally, lung cancer is categorized according to the histopathology and WHO classification method, ${ }^{21}$ while COPD can be divided into two most common phenotypes according to the dominant clinical feature and pathological changes: emphysema-predominant and chronic bronchitispredominant phenotypes. ${ }^{22,23}$

To confirm the above hypothesis, we conducted this study with a large sample to clarify the impact of COPD on lung cancer prognosis and further explored the relationships between COPD phenotypes and the prognosis of different histological subtypes of lung cancer.

\section{Materials and methods Patients}

We performed a retrospective cohort study using the clinical data of Qilu Hospital, Shandong University, Jinan, People's Republic of China. The study was approved by the Institutional Review Board of this hospital and was in accordance with the ethical standards and the Declaration of Helsinki (No 2015091). From October 2004 to December 2015, patients with newly and pathologically confirmed diagnosis of lung cancer who were preparing for lung cancer surgery were enrolled. All participants had undergone pulmonary function test (PFT). Histological subtypes of lung cancer were determined based on preoperative and/or postoperative histopathology reports and were categorized as squamous carcinoma, adenocarcinoma, small cell lung cancer (SCLC), large cell lung cancer (LCLC; including large cell neuroendocrine carcinoma), and other histological types according to 2015
WHO classification of lung tumors. ${ }^{21}$ Patients were excluded if they presented with simultaneous or sequential second primary cancers or had a history of asthma, bronchiectasis, tuberculosis, pulmonary fibrosis, or other confounding diseases. Data on age, sex, body mass index (BMI), smoking history, lung cancer histology, chest computed tomography (CT), therapy method, and other medical information were carefully collected for all subjects included in the study. The PFT data of all patients were derived from the MasterLab system (Jaeger, Hoechberg, Germany) of the hospital, including forced vital capacity (FVC), forced expiratory volume in 1 second $\left(\mathrm{FEV}_{1}\right)$, and raw data points (sampling every $40 \mathrm{~mL}$ of volume) of the maximum expiratory flow volume (MEFV) curve.

As a retrospective study, all data were anonymous. We declared that patients' data were confidential and did not compromise the patient's interests. After the approval of the Ethics Committee of Qilu Hospital of Shandong University, informed consent from participants was not required.

\section{Assessment of COPD}

All PFTs were performed and evaluated by experienced respiratory physicians on a computerized spirometer (MasterScreen, Jaeger) according to the American Thoracic Society/European Respiratory Society (ATS/ERS) recommendations. ${ }^{24}$ The GOLD criteria was used to diagnose and assign severity of COPD: patients with a postbronchodilator $\mathrm{FEV}_{1} / \mathrm{FVC}<0.70$ were classified as having $\mathrm{COPD} ; \mathrm{FEV}_{1} \geq 0.8$ was defined as mild, $0.5 \leq \mathrm{FEV}_{1}<0.8$ as moderate, $0.3 \leq \mathrm{FEV}_{1}<0.5$ as severe, and $\mathrm{FEV}_{1} \leq 0.3$ as extremely severe. ${ }^{25}$

\section{Identification of COPD phenotypes}

Previous studies have demonstrated that a sharp "angle of collapse" (airway collapse [AC]) in the MEFV curve was an effective indicator for emphysema. ${ }^{26,27}$ We referred to the Topalovic's method to make a quantitative measurement of AC. ${ }^{27}$ According to our previous research, ${ }^{28}$ the raw PFT data points of the MEFV curve were reestablished and analyzed by a computer model. The ACs were measured with standard procedures using the computer model based on Matlab software 8.5 (The MathWorks, Natick, MA, USA). AC $137^{\circ}$ was chosen as an optimal cutoff point for categorizing COPD phenotypes: emphysema-predominant phenotype $\left(\mathrm{AC} \leq 137^{\circ}\right)$ and nonemphysema-predominant phenotype $\left(\mathrm{AC}>137^{\circ}\right)$. A few COPD patients, whose raw PFT data were not available for AC measurement, were excluded from further analysis related to COPD phenotype. 


\section{Follow-up}

All patients were followed up to determine their survival status. These survival data were collected from the hospitals, the Civil Administration Bureau, the Public Security Bureaus, or the description of patient's family members. The primary end point of this study was overall survival (OS). OS was measured from the day of diagnosis to the date of death or date of last follow-up visit.

\section{Statistical analysis}

All statistical analyses were performed using SPSS version 19.0 for windows (IBM Corporation, Armonk, NY, USA). Continuous variables were expressed as mean $\pm \mathrm{SD}$, and comparison between the groups was done using Student's $t$-test. Categorical variables were presented as percentages, and comparison between the groups was done using the chi-squared test. Survival curves were generated using the Kaplan-Meier method, and the difference between the survival curves in relation to low and high levels of prognostic factors was tested using the log-rank test. Cox regression analysis was used to evaluate the HR as well as $95 \%$ confidence intervals. A two-sided $P$-value $<0.05$ was deemed statistically significant.

\section{Results}

\section{Patient characteristics}

A total of 2,222 patients with newly diagnosed lung cancer were enrolled in this study. The characteristics of patients are provided in Table 1 . The age of lung cancer patients was $60.2 \pm 9.5$ years. Of the total number of patients, $1,670(75.2 \%)$ were male and 1,187 (53.4\%) were current smokers or exsmokers. The histological subtypes identified were as follows: squamous carcinoma (792 [35.6\%]), adenocarcinoma (1,120 [50.4\%]), SCLC (152 [6.8\%]), LCLC (78 [3.5\%]), and other histologic types (including adenosquamous, carcinoma carcinoid tumors, sarcomatoid carcinoma, and pulmonary melanoma; 80 [3.6\%]). Moreover, 2,061 (92.8\%) lung cancers were at early stage (stage IA-IIB) and 1,821 (80.1\%) of all lung cancers had eventually undergone surgery.

The prevalence of COPD in lung cancer patients was $32.6 \%$. Five hundred forty $(74.6 \%)$ COPD patients were categorized as mild, 155 (21.4\%) were moderate, and 29 $(4.0 \%)$ were severe or extremely severe. Compared with lung cancer patients with non-COPD, those with COPD were older $(P<0.001)$, had a lower BMI $(P<0.001)$, and majority were male $(P<0.001)$ and smokers $(P<0.001)$. The proportion of squamous carcinoma was higher in patients with COPD, while adenocarcinoma was more frequently observed in patients with non-COPD. Furthermore, 656 (90.6\%) COPD patients had undergone computer quantitative measurements of AC. Seventy-five emphysema-predominant phenotype $\left(\mathrm{AC}=128.6^{\circ} \pm 7.0^{\circ}\right)$ and 581 nonemphysema-predominant phenotype $\left(\mathrm{AC}=151.1^{\circ} \pm 7.2^{\circ}\right)$ in COPD patients were identified. Other characteristics of the two phenotypes are shown in Table 2.

\section{OS analysis}

The median follow-up period was 49.9 months, with a follow-up rate exceeding 95\% (2,112 of 2,222 lung cancers). The 3-/5-year OS rates of lung cancers were $73.0 \% / 65.2 \%$ in COPD patients and were $79.5 \% / 73.3 \%$ in non-COPD patients. The Kaplan-Meier survival curves indicated that COPD, COPD severity, and its phenotypes were significantly associated with worse OS of lung cancers $(P<0.001)$. Besides, surgical treatment was also considered as one of the factors that significantly affects the prognosis of lung cancer $(P<0.001$, Figure 1$)$.

The HRs of factors related to lung cancer prognosis are shown in Table 3. In univariate analysis, the presence of COPD was associated with the decreased OS of lung cancer (HR=1.46, 95\% CI 1.20-1.76), and similarly both emphysema-predominant phenotype and nonemphysemapredominant phenotype of COPD significantly decreased the OS (HR=1.35, 95\% CI 1.20-1.53). However, surgical treatment and high BMI were demonstrated as prognostic protective factors (HR 0.44, 95\% CI 0.36-0.54; HR 0.95, 95\% CI 0.93-0.98). Multivariate Cox regression analysis showed that, after adjustment for age, sex, BMI, smoking status, and therapy method, COPD (especially emphysemapredominant phenotype) was significantly associated with the decreased OS of lung cancers (HR 1.28, 95\% CI 1.05-1.57; HR $1.84,95 \%$ CI 1.21-2.80). With the increased severity of $\mathrm{COPD}$, the prognosis of lung cancer was gradually worsened (HR 1.23, 95\% CI 1.08-1.39). Conversely, the presence of nonemphysema-predominant phenotype of COPD showed no impact on the prognosis of lung cancer (HR 1.14, 95\% CI 0.91-1.43). Furthermore, the same Cox regression model demonstrated that lower age was another prognostic protective factor besides surgical treatment and high BMI.

The HRs for OS according to different grades of COPD severity among lung cancer patients are shown in Table 4. In univariate analysis, the presence of any grades of COPD, especially those categorized as emphysema-predominant phenotype of COPD, was significantly associated with the decreased OS of lung cancer. Nonemphysema-predominant phenotype of moderate COPD also decreased the OS. 
Table I Characteristics of lung cancers

\begin{tabular}{|c|c|c|c|c|}
\hline Characteristics & $\begin{array}{l}\text { Entire cohort } \\
(n=2,222)\end{array}$ & $\begin{array}{l}\text { COPD } \\
(n=724)\end{array}$ & $\begin{array}{l}\text { Non-COPD } \\
(n=1,498)\end{array}$ & $P$-value \\
\hline Age, years (mean $\pm S D$ ) & $60.2 \pm 9.5$ & $62.6 \pm 8.5$ & $59.1 \pm 9.7$ & $<0.001$ \\
\hline Sex, n (\%) & & & & $<0.001$ \\
\hline Male & $\mathrm{I}, 670(75.2)$ & $636(87.8)$ & $\mathrm{I}, 034(69.0)$ & \\
\hline Female & $552(24.8)$ & $88(12.2)$ & $464(31.0)$ & \\
\hline $\mathrm{BMI}, \mathrm{kg} / \mathrm{m}^{2}($ mean $\pm \mathrm{SD})$ & $24.2 \pm 3.5$ & $23.7 \pm 3.5$ & $24.5 \pm 3.4$ & $<0.001$ \\
\hline Smoking status, $\mathrm{n}(\%)$ & & & & $<0.001$ \\
\hline Current and ex-smokers & I,I87 (53.4) & $499(68.9)$ & $688(45.9)$ & \\
\hline Nonsmokers & $\mathrm{I}, 035(46.6)$ & $225(3 I . I)$ & $810(54.1)$ & \\
\hline \multicolumn{5}{|l|}{ Histology, n (\%) } \\
\hline Squamous carcinoma & $792(35.6)$ & $34 I(47.1)$ & $45 I(30.1)$ & $<0.001$ \\
\hline Adenocarcinoma & $\mathrm{I}, \mathrm{I} 20(50.4)$ & $263(36.3)$ & $857(57.2)$ & $<0.001$ \\
\hline SCLC & $152(6.8)$ & $65(9.0)$ & $87(5.8)$ & 0.004 \\
\hline LCLC & $78(3.5)$ & $31(4.3)$ & $47(3.1)$ & 0.107 \\
\hline Other subtypes ${ }^{\mathrm{b}}$ & $80(3.6)$ & $24(3.3)$ & $56(3.7)$ & 0.356 \\
\hline \multicolumn{5}{|l|}{ Treatment, n (\%) } \\
\hline Surgery & I,82। (82.0) & $549(75.8)$ & $1,272(84.9)$ & $<0.001$ \\
\hline Nonsurgery & $40 I(18.0)$ & $175(24.2)$ & $226(15.1)$ & \\
\hline Chemotherapy and/or radiotherapy & $327(14.7)$ & $139(19.2)$ & $188(12.6)$ & $<0.001$ \\
\hline Palliative therapy & $74(3.3)$ & $36(5.0)$ & $38(2.5)$ & $<0.001$ \\
\hline \multicolumn{5}{|l|}{ Clinical stage, n (\%) } \\
\hline I & I,598 (71.9) & $531(73.3)$ & I,067 (7I.2) & 0.314 \\
\hline II & $463(20.9)$ & $152(21.0)$ & $311(20.8)$ & 0.911 \\
\hline III-IV & $161(7.2)$ & $4 \mid(5.7)$ & $120(8.0)$ & 0.045 \\
\hline FVC, L (mean $\pm S D)$ & $3.3 \pm 0.8$ & $3.2 \pm 0.7$ & $3.4 \pm 0.8$ & $<0.001$ \\
\hline FVC\% predicted, $\%($ mean \pm SD) & $101.59 \pm 16.8$ & $96.1 \pm 18.0$ & $104.6 \pm 15.5$ & $<0.001$ \\
\hline $\mathrm{FEV}_{1}, \mathrm{~L}($ mean $\pm \mathrm{SD})$ & $2.5 \pm 0.7$ & $2.0 \pm 0.5$ & $2.7 \pm 0.6$ & $<0.001$ \\
\hline $\mathrm{FEV}_{1}$ predicted, \% (mean $\pm \mathrm{SD}$ ) & $95.0 \pm 20.3$ & $76.5 \pm 16.9$ & $103.9 \pm 15.2$ & $<0.001$ \\
\hline $\mathrm{FEV}_{1} / \mathrm{FVC}, \%($ mean $\pm \mathrm{SD})$ & $73.5 \pm 9.8$ & $61.9 \pm 6.4$ & $79.2 \pm 5.1$ & $<0.001$ \\
\hline \multicolumn{5}{|l|}{ COPD } \\
\hline No & $\mathrm{I}, 498(67.4)$ & 1 & $\mathrm{I}, 498(100)$ & \\
\hline Yes & $724(32.6)$ & $724(32.6)$ & 1 & \\
\hline \multicolumn{5}{|l|}{ COPD severity, n (\%) } \\
\hline Mild & $540(24.3)$ & $540(74.6)$ & l & \\
\hline Moderate & $155(7.0)$ & $155(21.4)$ & I & \\
\hline Severe/extremely severe & $29(1.3)$ & $29(4.0)$ & I & \\
\hline \multicolumn{5}{|l|}{ COPD phenotype, n (\%) } \\
\hline Emphysema-predominant & $75(3.4)$ & $75(10.4)$ & I & \\
\hline Nonemphysema-predominant & $581(26.1)$ & $581(80.2)$ & l & \\
\hline Unclassified & $68(3.1)$ & $68(9.4)$ & l & \\
\hline
\end{tabular}

Notes: a Comparison between COPD and non-COPD. 'OOther subtypes including adenosquamous, carcinoma carcinoid tumors, sarcomatoid carcinoma, and pulmonary melanoma. /, not applicable.

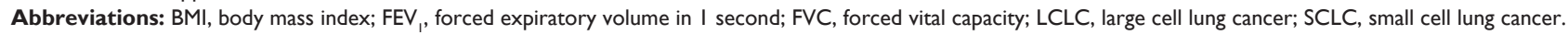

Multivariate Cox regression analysis showed that after adjustment for age, sex, BMI, smoking status, and therapy method, emphysema-predominant phenotype of moderate and severe COPD was significantly associated with the decreased OS of lung cancers (HR 1.96, 95\% CI 1.12-3.46; HR 2.37, 95\% CI 1.04-5.40). However, the presence of nonemphysemapredominant phenotype of any grades of COPD showed no impact on the prognosis of lung cancer.

Subgroup analysis indicated that there were some differences in the prognosis of lung cancer among histological subtypes (Figure 2). Further multivariate Cox regression analysis stratified by histology demonstrated that after adjustment for age, sex, BMI, smoking status, and therapy method, emphysema-predominant phenotype of COPD was significantly associated with the decreased OS of squamous carcinoma (HR 2.53, 95\% CI 1.49-4.30), while there was no other significant relationship between COPD phenotypes and the prognosis of adenocarcinoma, SCLC, LCLC, and other histologic subtypes. Besides, surgical treatment, after adjustment, was still significantly associated with the increased OS of squamous carcinoma and adenocarcinoma (HR 0.43, 95\% CI 0.32-0.59; HR 0.42, 95\% CI 0.30-0.60). We also 
Table 2 Characteristics of COPD phenotypes

\begin{tabular}{|c|c|c|c|}
\hline Characteristics & $\begin{array}{l}\text { Emphysema- } \\
\text { predominant } \\
\text { phenotype }(n=75)\end{array}$ & $\begin{array}{l}\text { Nonemphysema- } \\
\text { predominant } \\
\text { phenotype }(n=58 \mathrm{I})\end{array}$ & $P$-value \\
\hline Age, years (mean $\pm S D)$ & $63.5 \pm 7.9$ & $62.4 \pm 8.6$ & 0.291 \\
\hline Sex, n (\%) & & & 0.033 \\
\hline Male & 7I (94.7) & 505 (86.9) & \\
\hline Female & $4(5.3)$ & $76(13.1)$ & \\
\hline $\mathrm{BMI}, \mathrm{kg} / \mathrm{m}^{2}($ mean $\pm \mathrm{SD})$ & $23.3 \pm 3.7$ & $23.3 \pm 3.4$ & 0.348 \\
\hline Smoking status, n (\%) & & & 0.082 \\
\hline Current and ex-smokers & $46(61.3)$ & 407 (70.1) & \\
\hline Nonsmokers & $29(38.7)$ & 174 (29.9) & \\
\hline FVC, L (mean \pm SD) & $2.9 \pm 0.8$ & $3.3 \pm 0.7$ & $<0.001$ \\
\hline FVC\% predicted, \% (mean \pm SD) & $86.4 \pm 21.9$ & $96.8 \pm 16.4$ & $<0.001$ \\
\hline $\mathrm{FEV}_{1}, \mathrm{~L}($ mean $\pm \mathrm{SD})$ & $1.7 \pm 0.6$ & $2.0 \pm 0.5$ & $<0.001$ \\
\hline 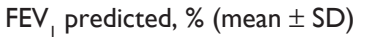 & $64.4 \pm 23.6$ & $77.6 \pm 14.6$ & $<0.001$ \\
\hline $\mathrm{FEV}_{\mathrm{I}} / \mathrm{FVC}, \%($ mean $\pm \mathrm{SD})$ & $56.6 \pm 10.8$ & $62.5 \pm 5.4$ & $<0.001$ \\
\hline$A C$ & $128.6 \pm 7.0$ & $151.2 \pm 7.2$ & $<0.001$ \\
\hline \multicolumn{4}{|l|}{ COPD severity, n (\%) } \\
\hline Mild & $22(29.3)$ & $464(79.9)$ & $<0.001$ \\
\hline Moderate & $36(48.0)$ & $107(\mid 8.4)$ & $<0.001$ \\
\hline Severe/extremely severe & $17(22.7)$ & $10(1.7)$ & $<0.001$ \\
\hline \multicolumn{4}{|l|}{ Histology, n (\%) } \\
\hline Squamous carcinoma & $41(54.7)$ & $270(46.5)$ & 0.112 \\
\hline Adenocarcinoma & $17(22.7)$ & $229(39.6)$ & 0.003 \\
\hline SCLC & II (I4.7) & $46(7.9)$ & 0.048 \\
\hline LCLC & $4(5.3)$ & $21(3.6)$ & 0.318 \\
\hline Other subtypes ${ }^{\mathrm{b}}$ & $2(2.7)$ & $15(2.6)$ & 0.598 \\
\hline Treatment, n (\%) & & & 0.054 \\
\hline Surgery & $50(66.7)$ & $442(76.1)$ & \\
\hline Nonsurgery & $25(33.3)$ & 139 (23.9) & \\
\hline
\end{tabular}

Notes: ${ }^{a}$ Comparison between emphysema-predominant phenotype and nonemphysema-predominant phenotype. ${ }^{b}$ Other subtypes include adenosquamous, carcinoma carcinoid tumors, sarcomatoid carcinoma, and pulmonary melanoma.

Abbreviations: AC, airway collapse; BMI, body mass index; FEV , forced expiratory volume in I second; FVC, forced vital capacity; LCLC, large cell lung cancer; SCLC, small cell lung cancer.

found a weak but significant effect of BMI on the prognosis of adenocarcinoma, where high BMI was associated with the increased OS (HR 0.93, 95\% CI 0.89-0.98, Table 5).

\section{Discussion}

This study explored insight into the association between COPD phenotypes and the prognosis of specific lung cancer histological subtype. Our analysis revealed that after adjustment for age, sex, BMI, smoking status, and therapy method, COPD, especially emphysema-predominant phenotype, was an independent prognostic risk factor for squamous carcinoma. However, COPD and its phenotypes were not significantly associated with the prognosis of other common subtypes of lung cancer.

In recent decades, the treatment of lung cancer has achieved great medical advances, but the survival rate of lung cancer is still very low. ${ }^{2}$ It is therefore important to identify factors related to the prognosis of lung cancer. Recently, COPD is considered to be a potential factor that affects the development of lung cancer. Some studies have reported that COPD was closely related to the occurrence of lung cancer. A prospective study has revealed that the lung cancer incidence in COPD patients was up to 16.7 per 1,000 person-years. ${ }^{12}$ Moreover, previous studies have reported that approximately $40 \%-70 \%$ of lung cancers coexist with COPD. ${ }^{13-15,18,29}$ Results of our study revealed a high prevalence of COPD: $32.8 \%$ out of 2,222 lung cancer patients. This suggested that the lowest percentages published thus far has avoided overdiagnosis by self-reporting of COPD ${ }^{14}$ and was not performed only in population who are at higher risk (eg, smokers and advanced age). ${ }^{13,15,30}$ The prevalence of COPD in this study should be much closer to that in overall lung cancer population and was higher than that in social population. ${ }^{31}$ However, the impact of COPD on the survival of patients with lung cancer remains ambiguous.

Some studies have reported that the presence of COPD showed an unfavorable effect on the survival of lung cancer patients, ${ }^{19,32,33}$ but others disagree. ${ }^{20,29,34}$ One of the important 
A

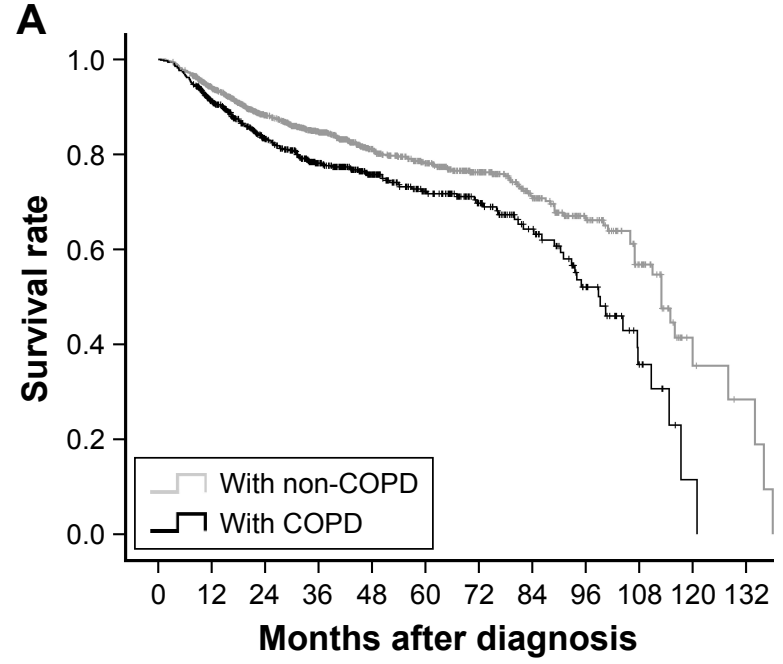

C

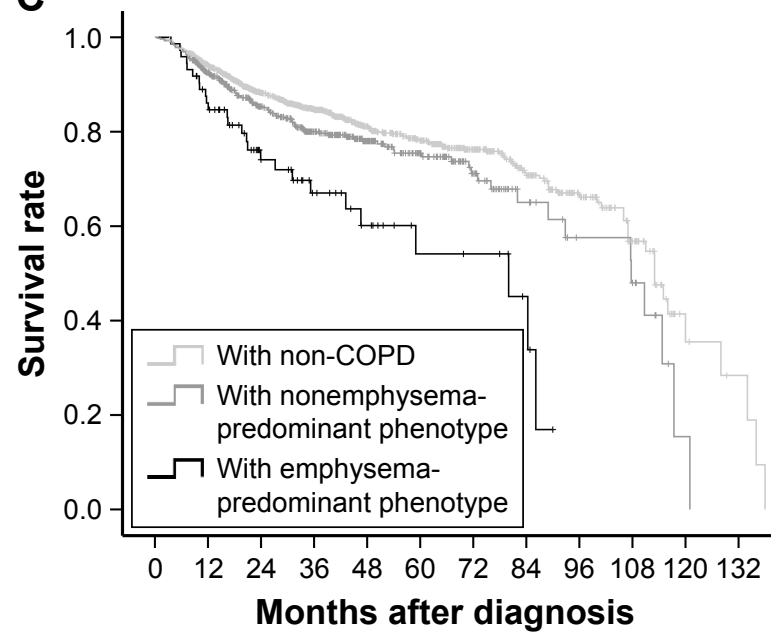

B

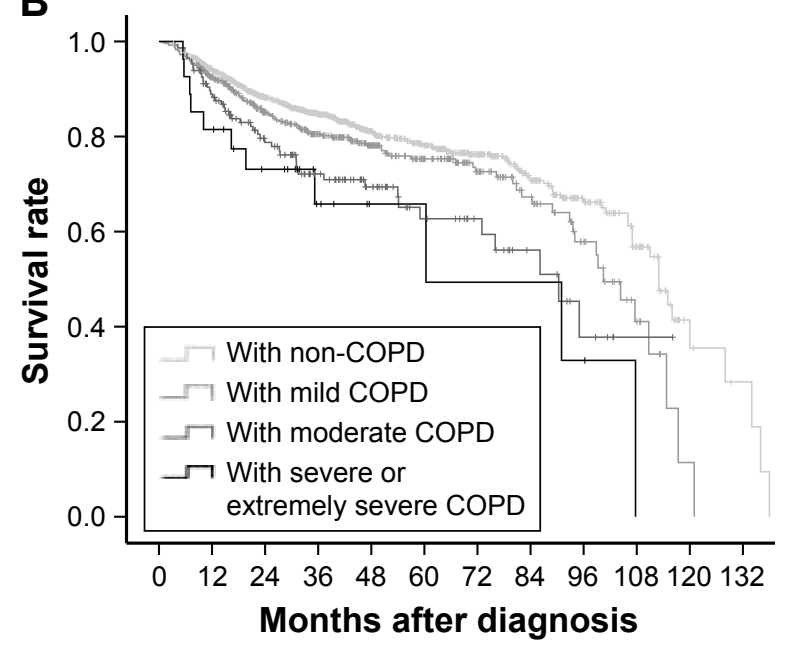

D

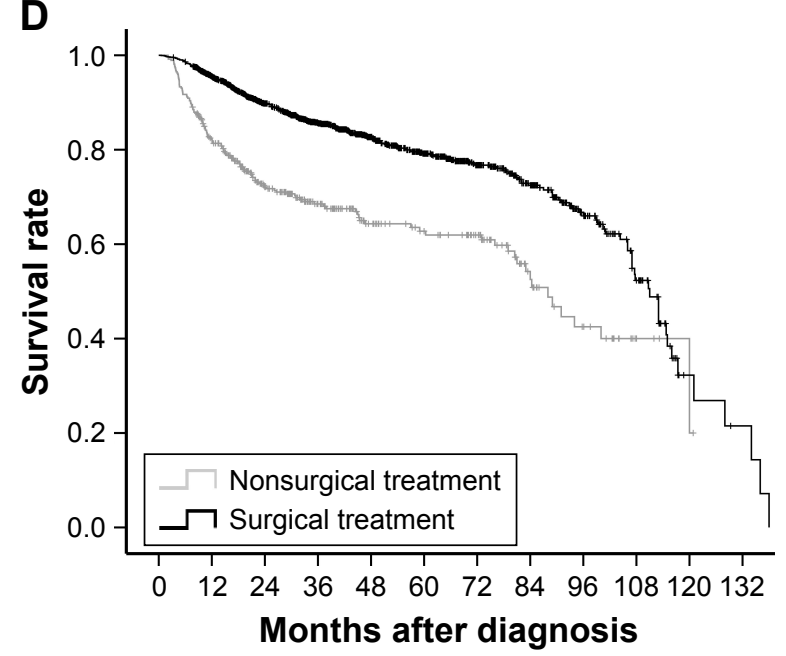

Figure I Kaplan-Meier curves of overall survival of lung cancer.

Notes: (A) Overall survival curves stratified by COPD $(P<0.00 \mathrm{I})$. (B) Overall survival curves stratified by COPD severity $(P<0.00 \mathrm{I})$. (C) Overall survival curves stratified by COPD phenotype $(P<0.00 \mathrm{I})$. (D) Overall survival curves stratified by treatment method $(P<0.00 \mathrm{I})$.

Table 3 HRs for overall survival according to clinicopathologic variables among lung cancer patients

\begin{tabular}{|c|c|c|c|c|c|c|}
\hline \multirow[t]{2}{*}{ Variables } & \multicolumn{3}{|c|}{ Univariate analysis } & \multicolumn{3}{|c|}{ Multivariate Cox regression $^{\mathrm{a}}$} \\
\hline & HR & $95 \% \mathrm{Cl}$ & $P$-value & HR & $95 \% \mathrm{Cl}$ & $P$-value \\
\hline COPD (present) & 1.46 & $1.20-1.76$ & $<0.001$ & 1.28 & $1.05-1.57$ & $0.016^{\mathrm{b}}$ \\
\hline COPD severity (increase) & 1.35 & $1.20-1.53$ & $<0.001$ & 1.23 & $1.08-1.39$ & $0.002^{c}$ \\
\hline Emphysema-predominant phenotype (present) & 2.45 & $1.63-3.67$ & $<0.001$ & 1.84 & $1.21-2.80$ & $0.004^{d}$ \\
\hline Nonemphysema-predominant phenotype (present) & 1.27 & $1.03-1.59$ & 0.029 & 1.11 & $0.91-1.43$ & $0.265^{e}$ \\
\hline Age (increase) & 1.01 & $1.00-1.02$ & 0.017 & 1.01 & $1.00-1.02$ & $0.033^{b}$ \\
\hline BMI (increase) & 0.95 & $0.93-0.98$ & $<0.001$ & 0.96 & $0.94-0.99$ & $0.003^{b}$ \\
\hline Sex (female) & 0.80 & $0.64-1.01$ & 0.059 & 0.82 & $0.62-1.07$ & $0.144^{b}$ \\
\hline Smoking status (smokers) & 1.04 & $0.86-1.26$ & 0.658 & 0.88 & $0.7 I-I .10$ & $0.263^{b}$ \\
\hline Surgery (yes) & 0.44 & $0.36-0.54$ & $<0.001$ & 0.46 & $0.37-0.56$ & $<0.00 \mathrm{I}^{\mathrm{b}}$ \\
\hline
\end{tabular}

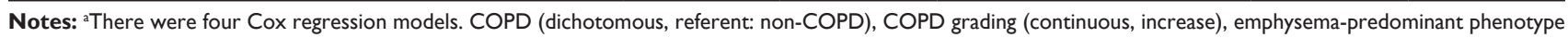
of COPD (dichotomous, referent: non-COPD), and nonemphysema-predominant phenotype of COPD (dichotomous, referent: non-COPD) were, respectively, distributed in models I, 2, 3, and 4. Age (continuous, increase), BMI (continuous, increase), sex (dichotomous, referent: male), smoking status (dichotomous, referent: nonsmoking), and surgery (dichotomous, referent: nonsurgery) were common variables of models I-4; 'bodel I; 'Model 2; 'Model 3; ${ }^{~}$ Model 4.

Abbreviation: BMI, body mass index. 
Table 4 HRs for overall survival according to different phenotypes of different severities of COPD among lung cancer patients

\begin{tabular}{|c|c|c|c|c|c|c|}
\hline \multirow[t]{2}{*}{ COPD $^{a}$} & \multicolumn{3}{|c|}{ Univariate analysis } & \multicolumn{3}{|c|}{ Multivariate Cox regression ${ }^{\mathrm{b}}$} \\
\hline & HR & $95 \% \mathrm{Cl}$ & $P$-value & HR & $95 \% \mathrm{Cl}$ & $P$-value \\
\hline \multicolumn{7}{|l|}{ Total COPD } \\
\hline Mild COPD & 1.29 & $1.04-1.6 \mid$ & 0.021 & 1.18 & $0.94-1.48$ & 0.156 \\
\hline Moderate COPD & 1.85 & $1.35-2.53$ & $<0.001$ & 1.52 & $1.10-2.10$ & 0.012 \\
\hline Severe/extremely severe COPD & 2.55 & $1.39-4.66$ & 0.002 & 1.97 & $1.06-3.63$ & 0.031 \\
\hline \multicolumn{7}{|l|}{ Emphysema-predominant phenotype } \\
\hline Mild COPD & 2.16 & $1.02-4.57$ & 0.045 & 1.44 & $0.67-3.09$ & 0.352 \\
\hline Moderate COPD & 2.31 & $1.32-4.03$ & 0.003 & 1.96 & $1.12-3.46$ & 0.019 \\
\hline Severe/extremely severe COPD & 3.38 & $1.50-7.62$ & 0.003 & 2.37 & $1.04-5.40$ & 0.040 \\
\hline \multicolumn{7}{|c|}{ Nonemphysema-predominant phenotype } \\
\hline Mild COPD & 1.15 & $0.90-1.47$ & 0.249 & 1.07 & $0.83-1.37$ & 0.622 \\
\hline Moderate COPD & 1.70 & $1.15-2.52$ & 0.008 & 1.38 & $0.92-2.07$ & 0.118 \\
\hline Severe/extremely severe COPD & 2.31 & $0.86-6.22$ & 0.096 & 1.95 & $0.72-5.32$ & 0.191 \\
\hline
\end{tabular}

Notes: aCompared with non-COPD; abAdjusted by age (continuous), BMI (continuous), sex (dichotomous), smoking status (dichotomous), and surgery (dichotomous). Abbreviation: BMI, body mass index.

limitations of previous studies was the enrollment of small number of lung cancer patients, which might be a potential explanation for these inconsistent results. Whereas in our large sample size study, the 5-year OS rates of lung cancers with COPD were significantly lower than that of lung cancers without COPD. The results were higher than the overall 5 -year survival in overall lung cancer population ${ }^{2}$ but were consistent with OS rates in patients undergoing surgery. ${ }^{19}$ The reason for this was due to the involvement of earlystage (stage IA-IIB) lung cancers who were preparing for lung cancer surgery in this study. At last, $>82 \%$ of them had undergone surgery. Moreover, we observed that patients with COPD had increased risk of worsened OS of lung cancer, after adjusting for age, sex, BMI, smoking status, and therapy method. The results were in line with another study conducted

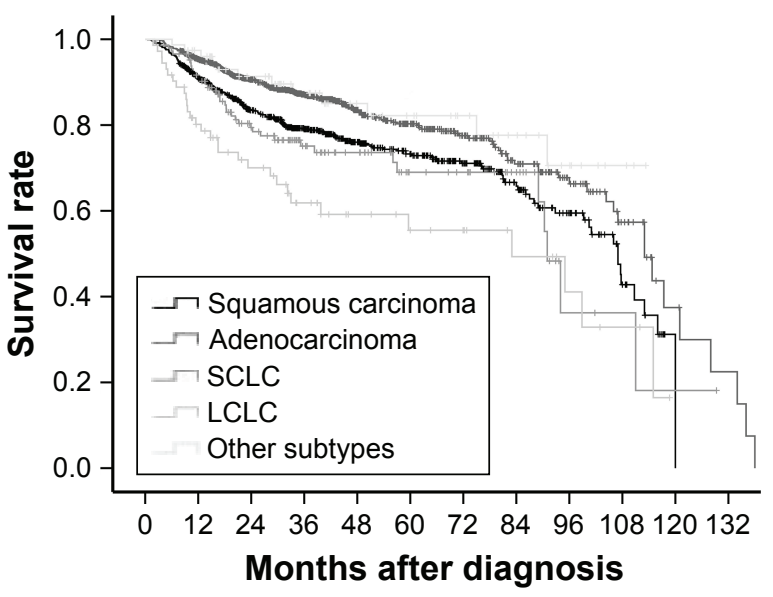

Figure 2 Kaplan-Meier curves of overall survival of different histological subtypes of lung cancer.

Note: Overall survival curves stratified by histology $(P<0.00 \mathrm{I})$.

Abbreviations: LCLC, large cell lung cancer; SCLC, small cell lung cancer. in patients with early-stage NSCLC. ${ }^{33}$ To the best of our knowledge, this is a study with the largest sample size that assessed the impact of COPD on OS of lung cancer.

It is well known that lung cancer and COPD are both heterogeneous diseases, and so there arises a question of whether there is any specific relationship between COPD phenotypes and the prognosis related to different histologic subtypes of lung cancer? Majority of the studies have been performed in NSCLC patients but were insufficient to provide enough information on histological subtypes. The cases in this study were collected over for a decade and included all common lung cancer subtypes. What is more, the proportion of each subtype was very close to the epidemiological distribution of lung cancer subtypes..$^{35}$ Lung cancers were categorized based on biopsy or operative histology, which was easier to identify compared with the classification of COPD phenotypes. Visual semiquantitative and quantitative $\mathrm{CT}$ assessments of emphysema are common methods to identify COPD phenotypes. ${ }^{36}$ Whereas the hard obtainable CT images and complicated nature of the procedure of $\mathrm{CT}$ assessment limit its usage in retrospective clinical studies. However, PFT is routinely used for patients with chronic airway disease and for lung cancers undergoing preoperative evaluations, and the results and raw data are much easier to obtain. In addition, computer quantification of $\mathrm{AC}$ on MEFV curve has been proved to be an alternative method for predicting the presence of emphysema, which consequently facilitates the emphysemapredominant COPD phenotype determination. ${ }^{26-28}$ In this study, we categorized COPD into emphysema-predominant phenotype and nonemphysema-predominant phenotype according to the computer quantification of AC. Our results were obtained on disease heterogeneity perspective, which 
Table 5 Impact of COPD and COPD phenotypes on overall survival of lung cancer stratified by histology

\begin{tabular}{|c|c|c|c|c|c|}
\hline Variables $^{\mathrm{a}}$ & $\begin{array}{l}\text { Squamous } \\
\text { carcinoma }\end{array}$ & Adenocarcinoma $^{b}$ & $\mathbf{S C L C}^{\mathrm{b}}$ & $\operatorname{LCLC}^{b}$ & Other subtypes $^{b}$ \\
\hline COPD (present) ${ }^{c}$ & $1.39(1.03-1.88)^{\#}$ & $1.29(0.92-1.83)^{*}$ & $1.16(0.60-2.23)^{*}$ & $0.84(0.34-2.06)^{*}$ & $1.04(0.29-3.75)^{*}$ \\
\hline COPD severity (increase) ${ }^{d}$ & $1.28(1.07-1.53)^{\#}$ & $1.21(0.95-1.56)^{*}$ & $1.06(0.74-1.52)^{*}$ & $0.88(0.48-1.59)^{*}$ & $0.81(0.29-2.29)^{*}$ \\
\hline $\begin{array}{l}\text { Emphysema-predominant } \\
\text { phenotype (present) }\end{array}$ & $2.53(1.49-4.30)^{\#}$ & $0.96(0.30-3.06)^{*}$ & $0.84(0.18-3.86)^{*}$ & $1.03(0.2 \mathrm{I}-4.96)^{*}$ & $4.67(0.02-110)^{*}$ \\
\hline $\begin{array}{l}\text { Nonemphysema-predominant } \\
\text { Phenotype (present) }\end{array}$ & $1.09(0.78-1.52)^{*}$ & $1.34(0.92-1.94)^{*}$ & $\mathrm{I} .0 \mathrm{I}(0.45-2.25)^{*}$ & $0.46(0.13-1.62)^{*}$ & $1.09(0.22-5.37)^{*}$ \\
\hline Age (increase) ${ }^{c}$ & I.0I $(0.99-1.03)^{*}$ & $1.01(0.99-1.03)^{*}$ & $0.99(0.96-1.03)^{*}$ & $1.01(0.97-1.06)^{*}$ & $1.03(0.97-1.10)^{*}$ \\
\hline BMI (increase) ${ }^{c}$ & $0.99(0.95-1.03)^{*}$ & $0.93(0.89-0.98)^{\#}$ & $0.99(0.91-1.08)^{*}$ & $0.90(0.80-1.01)^{*}$ & $1.04(0.92-1.18)^{*}$ \\
\hline Sex $(\text { female })^{c}$ & $1.32(0.80-2.19)^{*}$ & $0.74(0.50-1.09)^{*}$ & $1.48(0.53-4.10)^{*}$ & $0.87(0.23-3.23)^{*}$ & I.47 $(0.29-7.53)^{*}$ \\
\hline Smoking status (smokers) ${ }^{c}$ & $0.86(0.62-1.21)^{*}$ & $0.82(0.57-1.17)^{*}$ & $1.70(0.67-4.32)^{*}$ & $0.33(0.13-0.83)^{\#}$ & $1.14(0.25-5.29)^{*}$ \\
\hline Surgery $(\text { yes })^{c}$ & $0.43(0.32-0.59)^{\#}$ & $0.42(0.30-0.60)^{\#}$ & $0.60(0.3 \mathrm{I}-\mathrm{I} .89)^{*}$ & $1.08(0.37-3.18)^{*}$ & $0.78(0.09-6.82)^{*}$ \\
\hline
\end{tabular}

Notes: ${ }^{a}$ There were four Cox regression models, and each lung cancer subtypes was analyzed, respectively. COPD (dichotomous, referent: non-COPD), COPD grading (continuous, increase), emphysema-predominant phenotype of COPD (dichotomous, referent: non-COPD), and nonemphysema-predominant phenotype of COPD (dichotomous, referent: non-COPD) were, respectively, distributed in models I, 2, 3, and 4. Age (continuous, increase), BMI (continuous, increase), sex (dichotomous, referent: male), smoking status (dichotomous, referent: nonsmoking), and surgery (dichotomous, referent: nonsurgery) were common variables of models I-4; b $\mathrm{HR}$ ( $95 \% \mathrm{Cl}$ ); cModel I; ${ }^{d}$ Model 2; eModel 3; 'Model 4; ${ }^{*} P<0.05 ; * P>0.05$.

Abbreviations: BMI, body mass index; LCLC, large cell lung cancer; SCLC, small cell lung cancer.

showed that COPD, especially the emphysema-predominant phenotype was significantly associated with worsened OS of squamous carcinoma. Also, there were no other significant relationships between COPD phenotypes and prognosis of adenocarcinoma, SCLC, LCLC, and other histologic subtypes. Zhai et al have indicated that the presence of COPD was associated with worsened survival outcomes in patients with squamous carcinoma. ${ }^{33}$ Ueda et al have found that CT-diagnosed emphysema, but not airway obstruction, was associated with poor prognosis in smokers with early-stage lung cancer. ${ }^{37}$ A prospective study conducted by Turner et al have also reported that lung cancer mortality was significantly associated with emphysema, but not with chronic bronchitis. ${ }^{16}$ Gullón et al have also shown that emphysema was an adverse prognostic factor in NSCLC. ${ }^{38}$ Adding to these, our results demonstrated that disease heterogeneity might be another important reason for the cause of inconsistency among previously reported research results. In addition, we demonstrated that other factors related to the prognosis of lung cancer, such as BMI, smoking, and therapy method, were also affected by the disease heterogeneity.

A problem still exists that should not be ignored. In this study, the prevalence of moderate and more severe COPD in emphysema-predominant phenotype was significantly higher than those in nonemphysema-predominant phenotype of COPD. Our study also found that the OS of lung cancer was gradually worsened with the increased severity of COPD. One could argue whether the effect of COPD phenotype on the prognosis of lung cancer should be attributed to COPD severity. In order to solve this argument, further analysis was performed and found that nonemphysema-predominant phenotype, even those classified into moderate or more severe COPD, showed no significant effect on the prognosis of lung cancer. So, we emphasized the impact of COPD phenotype on the prognosis of lung cancer, which is more important than that of COPD severity.

The mechanisms through which COPD influence the prognosis of lung cancer still remain unclear. Chronic inflammation, DNA repair capacity, and abnormal apoptosis have been identified as potential common mechanisms. ${ }^{39-46}$ Moreover, COPD was associated with several clinical comorbidities, which may also affect the prognosis of lung cancer. ${ }^{47}$ Researchers have pointed out that the heterogeneous nature of these two diseases has hampered the research progress toward the mechanistic links between COPD and the occurrence of lung cancer. ${ }^{48,49}$ Our evaluation suggests that the mechanistic link between COPD and the development of lung cancer was also affected by disease heterogeneity. Previous evidences indicated that our hypothesis was biologically plausible. It has been shown that the matrix metalloproteinase is widely upregulated in emphysema and is associated with the occurrence of lymphovascular invasion and postoperative recurrence of lung cancer. ${ }^{50}$ So, lung cancer coexisting with emphysema is considered to be more aggressive. Schiavon et al have commented that compared with adenocarcinoma without COPD, adenocarcinoma with COPD tends to be less invasive ${ }^{51}$ Further studies from the perspective of disease heterogeneity are required for better understanding of the mechanistic link between COPD and the prognosis of lung cancer.

In addition to the strengths of this study, including the larger sample size, confirmed diagnosis of lung cancer and 
COPD and a focus on disease heterogeneity, there are several limitations. First, this study could not provide the impact of COPD on the progression-free survival of lung cancer due to lack of relevant information. It remains uncertain regarding the impact of COPD on the recurrence of lung cancer. Second, the stage of lung cancer is one of the most important prognostic factors in the analyses of OS of lung cancer patients. The effect of lung cancer staging on lung cancer prognosis was not observed in this study. The reason for this might be that $92.8 \%$ of lung cancer patients were at early stage (stage IA-IIB) and the later stage was not the main reason for not receiving surgical treatment in this study. Moreover, we did not collect the information regarding the use of inhaled corticosteroids, which are commonly prescribed to COPD patients and also has a potential role in cancer prevention and outcomes. ${ }^{52-54}$ Further, well-designed prospective studies are required to solve these problems.

\section{Conclusion}

COPD, especially emphysema-predominant phenotype, was an independent prognostic risk factor for squamous carcinoma. However, COPD and its phenotypes were not significantly associated with the prognosis of adenocarcinoma, SCLC, LCLC, and other histologic subtypes. Results of this study provide important implications on the research of the mechanism between lung cancer and COPD and contributed to the clinical identification of patients with higher risk for lung cancer prognosis.

\section{Acknowledgments}

This work was supported by the National Natural Science Foundation of People's Republic of China (No 81370148 and No 81400029) and the National Key Research and Development Program of China (2016YFC0903603). Wei Wang and Shuang Dou are the co-first authors.

\section{Disclosure}

The authors report no conflicts of interest in this work.

\section{References}

1. Torre LA, Bray F, Siegel RL, Ferlay J, Lortet-Tieulent J, Jemal A. Global cancer statistics, 2012. CA Cancer J Clin. 2015;65(2):87-108.

2. Allemani C, Matsuda T, Di Carlo V, et al; CONCORD Working Group. Global surveillance of trends in cancer survival 2000-14 (CONCORD-3): analysis of individual records for 37513025 patients diagnosed with one of 18 cancers from 322 population-based registries in 71 countries. Lancet. 2018;391(10125):1023-1075.

3. Lozano R, Naghavi M, Foreman K, et al. Global and regional mortality from 235 causes of death for 20 age groups in 1990 and 2010: a systematic analysis for the Global Burden of Disease Study 2010. Lancet. 2012;380(9859):2095-2128.
4. Chen W, Zheng R, Baade PD, et al. Cancer statistics in China, 2015. CA Cancer J Clin. 2016;66(2):115-132.

5. Halbert RJ, Natoli JL, Gano A, Badamgarav E, Buist AS, Mannino DM. Global burden of COPD: systematic review and meta-analysis. Eur Respir J. 2006;28(3):523-532.

6. Burney PG, Patel J, Newson R, Minelli C, Naghavi M. Global and regional trends in COPD mortality, 1990-2010. Eur Respir J. 2015;45(5): 1239-1247.

7. Dai J, Yang P, Cox A, Jiang G. Lung cancer and chronic obstructive pulmonary disease: from a clinical perspective. Oncotarget. 2017;8(11): $18513-18524$.

8. Loomis D, Grosse Y, Lauby-Secretan B, et al; International Agency for Research on Cancer Monograph Working Group IARC. The carcinogenicity of outdoor air pollution. Lancet Oncol. 2013;14(13):1262-1263.

9. Moolgavkar SH, Holford TR, Levy DT, et al. Impact of reduced tobacco smoking on lung cancer mortality in the United States during 1975-2000. J Natl Cancer Inst. 2012;104(7):541-548.

10. Pesch B, Kendzia B, Gustavsson P, et al. Cigarette smoking and lung cancer - relative risk estimates for the major histological types from a pooled analysis of case-control studies. Int J Cancer. 2012;131(5): $1210-1219$.

11. Eisner MD, Anthonisen N, Coultas D, et al; Committee on Nonsmoking COPD, Environmental and Occupational Health Assembly. An official American Thoracic Society public policy statement: novel risk factors and the global burden of chronic obstructive pulmonary disease. Am J Respir Crit Care Med. 2010;182(5):693-718.

12. de Torres JP, Marín JM, Casanova C, et al. Lung cancer in patients with chronic obstructive pulmonary disease -incidence and predicting factors. Am J Respir Crit Care Med. 2011;184(8):913-919.

13. Young RP, Hopkins RJ, Christmas T, Black PN, Metcalf P, Gamble GD. COPD prevalence is increased in lung cancer, independent of age, sex and smoking history. Eur Respir J. 2009;34(2):380-386.

14. Schwartz AG, Cote ML, Wenzlaff AS, et al. Chronic obstructive lung diseases and risk of non-small cell lung cancer in women. $J$ Thorac Oncol. 2009;4(3):291-299.

15. Papi A, Casoni G, Caramori G, et al. COPD increases the risk of squamous histological subtype in smokers who develop non-small cell lung carcinoma. Thorax. 2004;59(8):679-681.

16. Turner MC, Chen Y, Krewski D, Calle EE, Thun MJ. Chronic obstructive pulmonary disease is associated with lung cancer mortality in a prospective study of never smokers. Am J Respir Crit Care Med. 2007; 176(3):285-290.

17. Wasswa-Kintu S, Gan WQ, Man SF, Pare PD, Sin DD. Relationship between reduced forced expiratory volume in one second and the risk of lung cancer: a systematic review and meta-analysis. Thorax. 2005;60(7):570-575.

18. Loganathan RS, Stover DE, Shi W, Venkatraman E. Prevalence of COPD in women compared to men around the time of diagnosis of primary lung cancer. Chest. 2006;129(5):1305-1312.

19. Qiang G, Liang C, Xiao F, et al. Impact of chronic obstructive pulmonary disease on postoperative recurrence in patients with resected non-small-cell lung cancer. Int J Chron Obstruct Pulmon Dis. 2015;11: 43-49.

20. Lee SJ, Lee J, Park YS, et al. Impact of chronic obstructive pulmonary disease on the mortality of patients with non-small-cell lung cancer. J Thorac Oncol. 2014;9(6):812-817.

21. Travis WD, Brambilla E, Nicholson AG, et al. The 2015 World Health Organization classification of lung tumors: impact of genetic, clinical and radiologic advances since the 2004 classification. J Thorac Oncol. 2015;10(9):1243-1260.

22. MacNee W. Computed tomography-derived pathological phenotypes in COPD. Eur Respir J. 2016;48(1):10-13.

23. Subramanian DR, Gupta S, Burggraf D, et al. Emphysema- and airwaydominant COPD phenotypes defined by standardised quantitative computed tomography. Eur Respir J. 2016;48(1):92-103.

24. Pellegrino R, Viegi G, Brusasco V, et al. Interpretative strategies for lung function tests. Eur Respir J. 2005;26(5):948-968. 
25. Vogelmeier CF, Criner GJ, Martinez FJ, et al. Global Strategy for the Diagnosis, Management and Prevention of Chronic Obstructive Lung Disease 2017 Report: GOLD Executive Summary. Respirology. 2017;22(3):575-601.

26. Healy F, Wilson AF, Fairshter RD. Physiologic correlates of airway collapse in chronic airflow obstruction. Chest. 1984;85(4): 476-481.

27. Topalovic M, Exadaktylos V, Peeters A, et al. Computer quantification of airway collapse on forced expiration to predict the presence of emphysema. Respir Res. 2013;14:131.

28. Wang W, Xie M, Dou S, Cui L, Xiao W. Computer quantification of "angle of collapse" on maximum expiratory flow volume curve for diagnosing asthma-COPD overlap syndrome. Int J Chron Obstruct Pulmon Dis. 2016;11:3015-3022.

29. Ytterstad E, Moe PC, Hjalmarsen A. COPD in primary lung cancer patients: prevalence and mortality. Int J Chron Obstruct Pulmon Dis. 2016;11:625-636.

30. Powell HA, Iyen-Omofoman B, Baldwin DR, Hubbard RB, Tata LJ. Chronic obstructive pulmonary disease and risk of lung cancer: the importance of smoking and timing of diagnosis. J Thorac Oncol. 2013;8(1):6-11.

31. Yin P, Wang H, Vos T, et al. A subnational analysis of mortality and prevalence of COPD in China from 1990 to 2013: findings from the Global Burden of Disease study 2013. Chest. 2016;150(6):1269-1280.

32. Sekine Y, Suzuki H, Yamada Y, Koh E, Yoshino I. Severity of chronic obstructive pulmonary disease and its relationship to lung cancer prognosis after surgical resection. Thorac Cardiovasc Surg. 2013;61(2):124-130.

33. Zhai R, Yu X, Shafer A, Wain JC, Christiani DC. The impact of coexisting COPD on survival of patients with early-stage non-small cell lung cancer undergoing surgical resection. Chest. 2014;145(2):346-353.

34. Izquierdo JL, Resano P, El Hachem A, Graziani D, Almonacid C, Sánchez IM. Impact of COPD in patients with lung cancer and advanced disease treated with chemotherapy and/or tyrosine kinase inhibitors. Int J Chron Obstruct Pulmon Dis. 2014;9:1053-1058.

35. Gabrielson E. Worldwide trends in lung cancer pathology. Respirology. 2006;11(5):533-538.

36. Han MK, Agusti A, Calverley PM, et al. Chronic obstructive pulmonary disease phenotypes: the future of COPD. Am J Respir Crit Care Med. 2010;182(5):598-604.

37. Ueda K, Jinbo M, Li TS, Yagi T, Suga K, Hamano K. Computed tomography-diagnosed emphysema, not airway obstruction, is associated with the prognostic outcome of early-stage lung cancer. Clin Cancer Res. 2006;12(22):6730-6736.

38. Gullón JA, Suárez I, Medina A, Rubinos G, Fernández R, González I. Role of emphysema and airway obstruction in prognosis of lung cancer. Lung Cancer. 2011;71(2):182-185.

39. Lee G, Walser TC, Dubinett SM. Chronic inflammation, chronic obstructive pulmonary disease, and lung cancer. Curr Opin Pulm Med. 2009;15(4):303-307.
40. O'Callaghan DS, O’Donnell D, O'Connell F, O'Byrne KJ. The role of inflammation in the pathogenesis of non-small cell lung cancer. J Thorac Oncol. 2010;5(12):2024-2036.

41. Zaynagetdinov R, Sherrill TP, Gleaves LA, et al. Chronic NF- $\kappa B$ activation links COPD and lung cancer through generation of an immunosuppressive microenvironment in the lungs. Oncotarget. 2016; 7(5):5470-5482.

42. Bosken CH, Wei Q, Amos CI, Spitz MR. An analysis of DNA repair as a determinant of survival in patients with non-small-cell lung cancer. J Natl Cancer Inst. 2002;94(14):1091-1099.

43. Anderson GP, Bozinovski S. Acquired somatic mutations in the molecular pathogenesis of COPD. Trends Pharmacol Sci. 2003; 24(2):71-76.

44. Zhou W, Gurubhagavatula S, Liu G, et al. Excision repair crosscomplementation group 1 polymorphism predicts overall survival in advanced non-small cell lung cancer patients treated with platinumbased chemotherapy. Clin Cancer Res. 2004;10(15):4939-4943.

45. Demedts IK, Demoor T, Bracke KR, Joos GF, Brusselle GG. Role of apoptosis in the pathogenesis of COPD and pulmonary emphysema. Respir Res. 2006;7:53.

46. Singhal S, Vachani A, Antin-Ozerkis D, Kaiser LR, Albelda SM. Prognostic implications of cell cycle, apoptosis, and angiogenesis biomarkers in non-small cell lung cancer: a review. Clin Cancer Res. 2005;11(11):3974-3986.

47. Corsonello A, Antonelli Incalzi R, Pistelli R, Pedone C, Bustacchini S, Lattanzio F. Comorbidities of chronic obstructive pulmonary disease. Curr Opin Pulm Med. 2011;17(Suppl 1):S21-S28.

48. Houghton AM. Mechanistic links between COPD and lung cancer. Nat Rev Cancer. 2013;13(4):233-245.

49. Schwartz AG, Cote ML. Epidemiology of lung cancer. Adv Exp Med Biol. 2016;893:21-41.

50. Murakami J, Ueda K, Sano F, Hayashi M, Nishimoto A, Hamano K. Pulmonary emphysema and tumor microenvironment in primary lung cancer. J Surg Res. 2016;200(2):690-697.

51. Schiavon M, Marulli G, Nannini N, et al. COPD-related adenocarcinoma presents low aggressiveness morphological and molecular features compared to smoker tumours. Lung Cancer. 2014;86(3):311-317.

52. Parimon T, Chien JW, Bryson CL, McDonell MB, Udris EM, Au DH. Inhaled corticosteroids and risk of lung cancer among patients with chronic obstructive pulmonary disease. Am J Respir Crit Care Med. 2007;175(7):712-719.

53. Liu SF, Kuo HC, Lin MC, et al. Inhaled corticosteroids have a protective effect against lung cancer in female patients with chronic obstructive pulmonary disease: a nationwide population-based cohort study. Oncotarget. 2017;8(18):29711-29721.

54. Raymakers AJ, McCormick N, Marra CA, Fitzgerald JM, Sin D, Lynd LD. Do inhaled corticosteroids protect against lung cancer in patients with COPD? A systematic review. Respirology. 2017;22(1):61-70.
International Journal of COPD

\section{Publish your work in this journal}

The International Journal of COPD is an international, peer-reviewed journal of therapeutics and pharmacology focusing on concise rapid reporting of clinical studies and reviews in COPD. Special focus is given to the pathophysiological processes underlying the disease, intervention programs, patient focused education, and self management protocols.
Dovepress

This journal is indexed on PubMed Central, MedLine and CAS. The manuscript management system is completely online and includes a very quick and fair peer-review system, which is all easy to use. Visit http://www.dovepress.com/testimonials.php to read real quotes from published authors. 